\title{
Phytophagous stink bugs (Hemiptera: Pentatomidae; Coreidae) associated with macadamia in South Africa
}

\author{
Pieter Schalk Schoeman
}

Agricultural Research Council—Institute for Tropical and Subtropical Crops, Nelspruit, South Africa; schalk@arc.agric.za

Received 19 April 2013; revised 20 May 2013; accepted 28 May 2013

Copyright (C 2013 Pieter Schalk Schoeman. This is an open access article distributed under the Creative Commons Attribution License, which permits unrestricted use, distribution, and reproduction in any medium, provided the original work is properly cited.

\section{ABSTRACT}

Bathycoelia natalicola (Distant) is the dominant stink bug on macadamias in South Africa. This insect occurred throughout the year but was particularly numerous during summer months when developing macadamia nuts were available on the trees. The presence of nymphs and adults throughout the winter as well as the absence of seasonal polyphenism indicates that true diapause may not occur in areas with mild subtropical climates. After harvest, during winter when no nuts were available, the winter stink bug complex consisting of Nezara pallidoconspersa Stal, Nezara prunasis Dallas and Atelocera raptoria Germarbecame was more numerous. The Nezara species do not breed in macadamias indicating that macadamia is possibly not a preferred host plant. Few individuals of the polyphagous pest, Pseudotheraptus wayi brown were recovered with the branch shaking technique suggesting that this technique is possibly not suitable to monitor for this insect. Considerable $P$. wayi damage levels were however, detected by dissecting prematurely aborted nuts.

Keywords: Bugs; Diapause; Bathycoelia natalicola; Pseudotheraptus wayi

\section{INTRODUCTION}

Indigenous stink bugs from the families Coreidae and Pentatomidae are responsible for annual crop losses ranging up to R50 million in the macadamia and avocado industries of South Africa alone [1]. Economic damage usually occurs at very low population levels (threshold value in macadamias is $\pm 0.4 /$ tree) [2]. This factor as well as the lack of suitable pheromones ensures that growers of both fruit industries experience considerable difficul- ties in assessing population levels of the most important pest species. Consequently many growers adopted a prophylactic spraying programme consisting typically of 4 - 6 synthetic pyrethroids. Initially this spraying programme produced exceptional results but recent reports indicate the proliferation of secondary pests.

The rapid expansion of the avocado and macadamia industries in South Africa, linked with the demand for environmentally and socially sustainable fruit production in traditional importing countries, is forcing South African growers to adopt a more environmentally sensitive approach to crop protection.

The avocado and macadamia industries in Australia are facing similar problems with the two indigenous coreid bugs: Amblypelta lutescens lutescens (Distant) and Amblypelta nitida Stal [3]. According to [4], the introduced pentatomid Halyomorpha halys (Stal) is becoming a serious problem for a number of fruit industries in the Mid-Atlantic States of the USA.

Apart from the studies of $[5,6]$ very little information is known about the effect of indigenous heteropterans on subtropical crops in South Africa. This population survey should therefore be regarded as a first step in the process of drafting an Integrated Pest Management (IPM) plan for these pests in South Africa.

\section{MATERIALS AND METHODS}

This survey was initiated on the $23^{\text {rd }}$ of November 2010 on the farm of the Agricultural Research Council's Institute for Tropical and Subtropical Crops (ARC-ITSC) in Nelspruit $\left(25^{\circ} 27^{\prime} 18.68 \mathrm{~S} 30^{\circ} 58^{\prime} 09.89 \mathrm{E}\right)$ in a mature unsprayed mixed cultivar macadamia orchard. A second mature unsprayed mixed cultivar macadamia orchard at Friedenheim near Nelspruit $\left(25^{\circ} 26^{\prime} 17.97 \mathrm{~S} 30^{\circ} 59^{\prime} 02.45 \mathrm{E}\right)$ was also monitored from 18 October 2011 to March 2013.

All the branches from the bottom 2 - $2.5 \mathrm{~m}$ of 10 randomly selected trees were shaken every week at both 
localities. All stink bugs that dropped were collected and counted.

Ten recently dropped nuts were also collected underneath 10 randomly selected trees at each locality. Nuts were dissected by removal of the soft developing shelland the insides of the husks were inspected for stylet puncture marks. Initial dissections were done during October 2011 when nuts were pea sized. This survey lasted up to mid-January 2012 when the insides of the husk turned brown which effectively obliterated any puncture marks.

\section{RESULTS AND DISCUSSION}

A total of 1716 stinkbugs (1408 B. natalicola and 308 other stinkbugs representing 14 species) were recovered from the Nelspruit trial site over a period of 29 months ( \pm 59 stink bugs/month). The Friedenheim trial site was similarly infested because 1243 stink bugs (1032 B. na- talicola bugs and 211 other bugs representing 14 species) were recovered over a period of 18 months $( \pm 69$ stink bugs/month). Average stink bug density for the Nelspruit trial was 1.72 bugs/tree/week while the Friedenheim locality had an average density of $1.75 /$ tree.

Apart from B. natalicola, Tables $\mathbf{1}$ and $\mathbf{2}$ indicate that only three species occurred in relatively large numbers namely Nezara pallidoconspersa Stal, Ateloceraraptoria Germarand Nezara prunasis Dallas. These three species were also numerous during previous surveys that were carried out by $[5,6]$.

Considerably less A. raptoria individuals were recovered with the branch shaking method when compared to the chemical knock down technique used by [6]. A. raptoria individuals are commonly observed on main trunks and branches of many indigenous and cultivated trees in subtropical areas of South Africa. According to [6] and [7] this insect may be regarded as a bark feeder but may

Table 1. Numbers and seasonal occurrence of dominant heteropterans recovered from a mature mixed cultivar macadamia orchard at Nelspruit with the branch shaking method from November 2010-March 2013.

\begin{tabular}{|c|c|c|c|c|c|c|c|}
\hline \multirow{2}{*}{\multicolumn{2}{|c|}{ Season }} & \multicolumn{5}{|c|}{ Dominant Heteroptera species collected } & \multirow{2}{*}{$\begin{array}{l}\text { Total number of } \\
\text { insects collected }\end{array}$} \\
\hline & & \multirow{2}{*}{$\begin{array}{c}\begin{array}{c}\text { Pseudotheraptus wayi } \\
\text { Brown }\end{array} \\
1\end{array}$} & \multirow{2}{*}{$\begin{array}{c}\begin{array}{c}\text { Atelocera raptoria } \\
\text { Germar }\end{array} \\
1\end{array}$} & \multirow{2}{*}{$\begin{array}{c}\begin{array}{c}\text { Bathycoelia natalicola } \\
\text { Distant }\end{array} \\
224\end{array}$} & \multirow{2}{*}{$\begin{array}{c}\text { Nezara pallidoconspersa } \\
\text { Stal } \\
9\end{array}$} & \multirow{2}{*}{$\begin{array}{c}\begin{array}{c}\text { Nezara prunasis } \\
\text { Dallas }\end{array} \\
1\end{array}$} & \\
\hline$\exists$ & 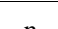 & & & & & & \multirow{4}{*}{237} \\
\hline 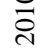 & $\%$ & 0.42 & 0.42 & 94.51 & 3.8 & 0.42 & \\
\hline \multirow{2}{*}{ 离 } & AR & 3 & 3 & 1 & 2 & 3 & \\
\hline & SO & Feb & Mar & Nov-Apr & Nov-Apr & Mar & \\
\hline \multirow{4}{*}{ 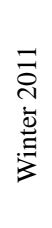 } & $\mathrm{N}$ & 2 & 3 & 179 & 48 & 48 & \multirow{4}{*}{288} \\
\hline & $\%$ & 0.69 & 1.04 & 62.15 & 16.67 & 16.67 & \\
\hline & AR & 4 & 3 & 1 & 2 & 2 & \\
\hline & SO & May, Jun & Jun, Aug & April-Sept & April-Sept & April-Sept & \\
\hline \multirow{4}{*}{ 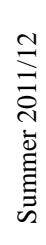 } & $\mathrm{N}$ & 6 & 1 & 218 & 10 & 2 & \multirow{4}{*}{243} \\
\hline & $\%$ & 2.47 & 0.41 & 89.71 & 4.12 & 0.82 & \\
\hline & $\mathrm{AR}$ & 3 & 5 & 1 & 2 & 4 & \\
\hline & $\mathrm{SO}$ & Oct, Nov, Feb, Mar & Nov & Oct-Mar & Oct-Mar & Oct & \\
\hline \multirow{4}{*}{ 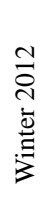 } & $\mathrm{N}$ & 3 & 5 & 321 & 68 & 37 & \multirow{4}{*}{446} \\
\hline & $\%$ & 0.67 & 1.12 & 71.97 & 15.25 & 8.30 & \\
\hline & $\mathrm{AR}$ & 5 & 4 & 1 & 2 & 3 & \\
\hline & $\mathrm{SO}$ & Apr, May, Jun & May, Jun, Jul & April-Sept & April-Sept & April-Sept & \\
\hline \multirow{4}{*}{ 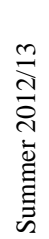 } & $\mathrm{N}$ & 8 & 11 & 466 & 4 & 4 & \multirow{4}{*}{502} \\
\hline & $\%$ & 1.59 & 2.19 & 92.83 & 0.8 & 0.8 & \\
\hline & $\mathrm{AR}$ & 3 & 2 & 1 & 4 & 4 & \\
\hline & $\mathrm{SO}$ & Oct, Nov, Jan, Feb, Mar & Oct-Mar & Oct-Mar & Dec, Jan, Mar & Oct, Jan, Mar & \\
\hline
\end{tabular}

$\mathrm{n}=$ total number of individuals, $\%$ = percentage of grand total of individuals caught, $\mathrm{AR}=$ Abundance ranking, SO = Seasonal occurrence. 
Table 2. Numbersand seasonal occurrence of dominantheteropterans recovered from a mature mixed cultivar macadamia orchard atFriedenheim with the branch shaking method from October 2011-March 2013.

\begin{tabular}{|c|c|c|c|c|c|c|c|}
\hline \multirow{2}{*}{\multicolumn{2}{|c|}{ Season }} & \multicolumn{5}{|c|}{ Dominant Heteroptera species collected } & \multirow{2}{*}{$\begin{array}{l}\text { Total number of } \\
\text { insects collected }\end{array}$} \\
\hline & & \multirow{2}{*}{$\begin{array}{c}\begin{array}{c}\text { Pseudotheraptus wayi } \\
\text { Brown }\end{array} \\
1\end{array}$} & \multirow{2}{*}{$\begin{array}{c}\text { Atelocera raptorial } \\
\text { Germar }\end{array}$} & \multirow{2}{*}{$\begin{array}{c}\begin{array}{c}\text { Bathycoelia natalicola } \\
\text { Distant }\end{array} \\
547\end{array}$} & \multirow{2}{*}{$\begin{array}{c}\begin{array}{c}\text { Nezara pallidoconspersa } \\
\text { Stal }\end{array} \\
3\end{array}$} & \multirow{2}{*}{$\begin{array}{c}\begin{array}{c}\text { Nezara prunasis } \\
\text { Dallas }\end{array} \\
5\end{array}$} & \\
\hline$\underset{\approx}{\approx}$ & $\mathrm{n}$ & & & & & & \multirow{4}{*}{576} \\
\hline$\overline{\text { నे }}$ & $\%$ & 0.17 & 1.04 & 94.97 & 0.52 & 0.87 & \\
\hline 峁 & AR & 5 & 2 & 1 & 4 & 3 & \\
\hline के & OR & Nov & Nov, Jan Feb, Mar & Oct-Mar & Nov, Jan & Nov, Jan, Mar & \\
\hline \multirow{4}{*}{ 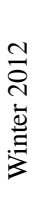 } & $\mathrm{n}$ & 1 & 36 & 219 & 21 & 92 & \multirow{4}{*}{379} \\
\hline & $\%$ & 0.26 & 9.5 & 57.78 & 5.54 & 24.27 & \\
\hline & AR & 5 & 3 & 1 & 4 & 2 & \\
\hline & OR & May & Apr-Sept & Apr-Sept & April-Jul & April-Aug & \\
\hline \multirow{4}{*}{ 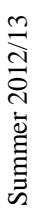 } & $\mathrm{n}$ & 1 & 16 & 266 & 0 & 1 & \multirow{4}{*}{288} \\
\hline & $\%$ & 0.35 & 5.56 & 92.36 & 0 & 0.35 & \\
\hline & AR & 3 & 2 & 1 & 4 & 3 & \\
\hline & OR & Mar & Nov, Dec, Jan, Mar & Oct-Mar & & Oct & \\
\hline
\end{tabular}

$\mathrm{n}=$ total number of individuals, $\%=$ percentage of grand total of individuals caught, AR = Abundance ranking, OR = Seasonal occurrence.

sometimes damage fruit. The branch shaking technique was probably not effective enough to dislodge considerable numbers.

Table 1 also indicated that N. pallidoconspersa occurred in relatively large numbers at the Nelspruit trial site. The abundance of this insect can possibly be related to large numbers of the alternative host plant Ricinus communis (castor oil) which grew in close proximity to the trial orchard.

Although small numbers of adult bugs were found in the Nelspruit locality throughout the year, Tables $\mathbf{1}$ and $\mathbf{2}$ indicate that they appeared to be more numerous from March-September. No nymphs were found in both orchards which indicate that macadamia is probably not a preferred host. Its stylet length is sufficient to penetrate the medial area of some cultivars [1] but because it is prolific when most macadamia nuts have already been harvested, it is probably not a pest of considerable economic significance.

According to Tables 1 and 2 surprisingly few individuals of the polyphagous pest: Pseudotheraptus wayi brown were recovered with the branch shaking method while the chemical knock down technique used by $[5,6]$ recovered considerably more. Unlike most pentatomids, these insects do not drop to the ground when disturbed but fly unobtrusively to nearby trees or hiding places. This aspect linked to their stealthy habits as well as their brown base colour made these insects very difficult to locate in shady macadamia orchards. Immature nut dissections during November-February (Figure 1) is proba-

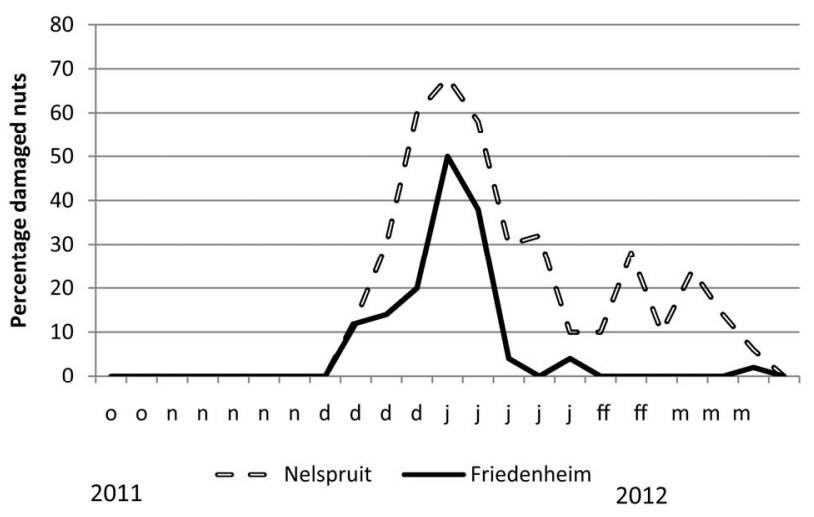

Figure 1. Relative seasonal abundance of aborted nuts with typical coconut bug damage symptoms during 2011/12.

bly a reliable method to determine the true magnitude of this pest in macadamia orchards as a large percentage of aborted nuts during this time showed typical symptoms of coconut bug infestation (Figure 2) (big sunken necrotic lesions in the developing shell as well as brown sticky lesions on the inside of the husk).

$B$. natalicola is able to breed in macadamias indicating that this crop is a suitable host. According to [8] stink bugs belonging to the Pentatomidae family overwinter mostly as adults in the temperate zone although exceptions do occur. According to Figures $\mathbf{3}$ and $\mathbf{4}$ it is clear that nymphs as well as adults were prolific throughout the entire winter in South Africa (April-August). Adults were present throughout the year but from August-December when nuts were either absent or immature no- 


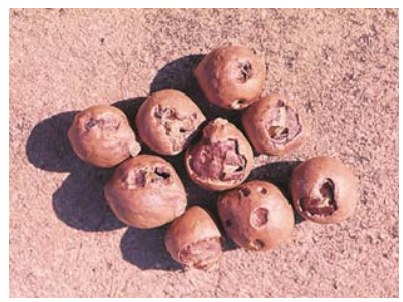

(a)

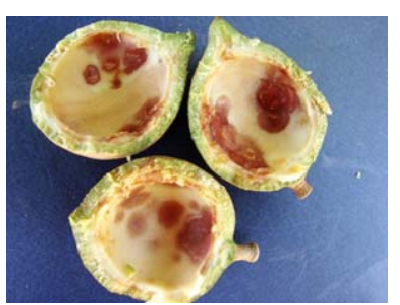

(b)
Figure 2. Damage to brown nutshells caused by Pseudotheraptus wayi brown (a) as well as lesions on the inside of the husk (b).

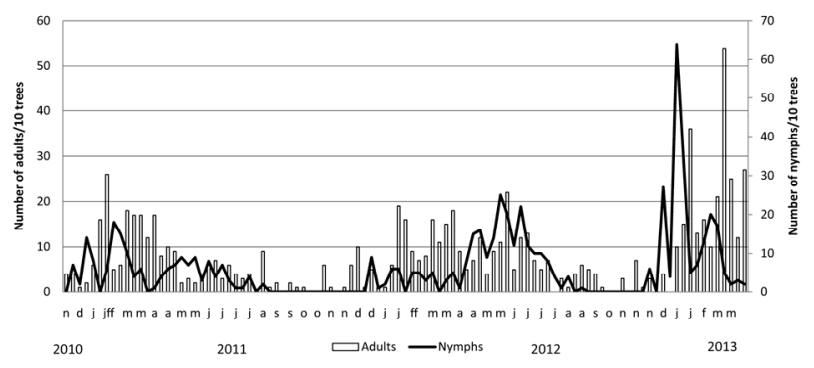

Figure 3. Relative seasonal abundance of adults and nymphs of the two spotted bug Bathycoelia natalicola at Nelspruit.

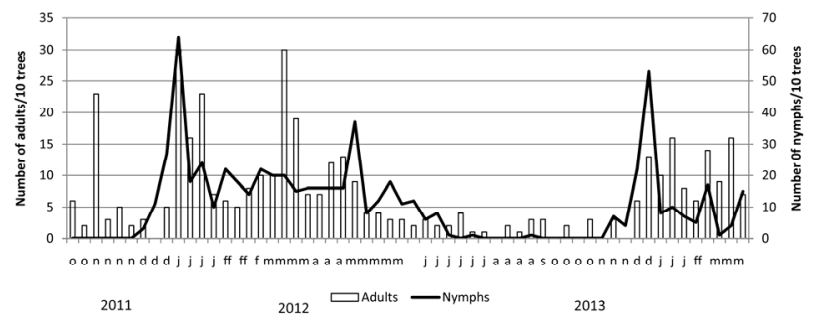

Figure 4. Relative seasonal abundance of adults and nymphs of the two spotted bug Bathycoelia natalicola at Friedenheim.

nymphs were observed. Due to the mild subtropical climate in the Nelspruit region as well as the abundance of nymphs during winter, it is therefore possible that scarcity of food during August-December may induce a form of reproductive diapause rather than temperature.

B. natalicola is the most abundant heteropteran in macadamias. When developing macadamia nuts are available on the trees during September to March every year this insect comprised $\pm 90 \%$ of all heteropterans recovered (Tables 1 and 2). During winter (April-August) when few nuts were available, Tables 1 and $\mathbf{2}$ indicate that comparatively fewer individuals wererecovered. At Friedenheim seven Heteroptera species were recovered during the summer and 10 at Nelspruit. The species diversity increased during winter as 10 species were recovered at Friedenheim and 13 at Nelspruit.

$N$. prunasis only occurred from March-September every year at both localities. No nymphs were found indicating that macadamia is possibly not a preferred host. This corresponds with the results of $[5,6]$. These insects were heterogeneously distributed and in some cases a number of individuals were caught in the same tree which could indicate aggregation behaviour.

Based on its stylet length of $3.8 \mathrm{~mm} \pm 0.4 \mathrm{~mm}(\mathrm{n}=10)$, this insect will not be able to damage mature nuts as the combined husk and shell thickness (kernel distance) of all mature macadamia cultivars is greater than the length of its stylet. This insect is also abundant when the mature crop has already been harvested which indicates that it possibly does not feed exclusively on nuts.

\section{CONCLUSIONS}

B. natalicola (Figure 5) is the dominant pentatomid on macadamias in South Africa and represents more than $90 \%$ of heteropterns recovered when immature nuts are present on the trees. After the nuts reached maturity during March/April, heteropterans with shorter mouthparts (winter complex) became more dominant. Apart from $B$. natalicola, A. raptoria and $P$. wayi, only mature insects were recovered which seems to indicate that macadamia is not a preferred host plant for the winter complex but may act as a temporary overwintering site. This observation is strengthened by the finding of [1] that the combined husk and kernel thicknesses of most mature nuts will prevent kernel feeding by these insects.

It is unsure whether the mild subtropical winters are able to induce true diapause of $B$. natalicola as described by $[8,9]$ or whether this insect merely undergoes low temperature or starvation induced dormancy. The absence of seasonal polyphenism certainly strengthens the case against diapause. Caged individuals of B. natalicola did not oviposit during June and July but initial egg laying was observed as early as the first week in August 2012. Population levels of B. natalicola during early spring is normally very low (Figures 3 and 4 ) and migration into the orchards only occur from October onwards when developing green nuts become available. Emigration of adults from macadamia orchards after harvest during May-July is very difficult to prove but must be regarded as a distinct possibility as it is probably a method these insects use to avoid unfavourable conese-

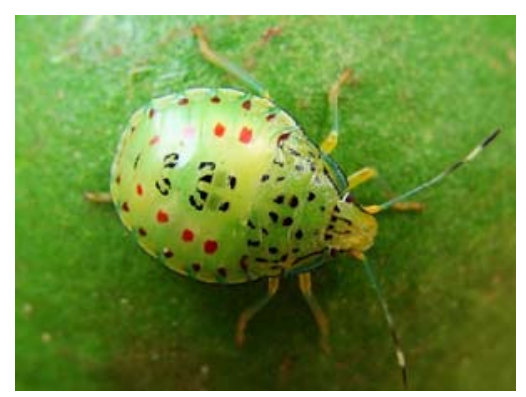

Figure 5. A third instar nymph of the two spotted bug Bathy- coelia natalicola (Distant) on a macadamia nut. 
quences of seasonality.

In South Africa, these insects are largely controlled with synthetic pyrethroids applied at fixed monthly intervals from just after flowering up to harvest (5 - 6 applications). Because these insects are endemic, they occur at very low numbers which makes threshold based control centre on monitoring very difficult. This report must therefore be regarded as an attempt to gain deeper understanding into the biology and relative seasonal abundance of this group of insects which will facilitate spray decision support in future.

\section{REFERENCES}

[1] Chou Schoeman, P.S. (2009) Key biotic components of the indigenous Tortricidae and Heteroptera complexes occurring on macadamia in South Africa. Ph.D. Dissertation, North West University, Potchefstroom.

[2] Schoeman, P.S. (2009) Integrated management of macadamia pests. Yearbook of the Southern African Macadamia Growers Association, 16, 23-29.

[3] Waite, G.K. and Huwer, R.K. (1998) Host plants of the fruitspotting bugs Amblypelta nitida Stal and Amblyseius lutescens lutescens (Distant) (Hemiptera: Coreidae) and their role in the bugs ecology. Australian Journal of En- tomology, 37, 340-349. doi:10.1111/j.1440-6055.1998.tb01594.x

[4] Nielsen, A.L. and Hamilton, G.C. (2009) Seasonal occurrence and impact of Halyomorpha halys (Hemiptera: Pentatomidae) in tree fruit. Journal of Economic Entomology 102, 1133-1140. doi:10.1603/029.102.0335

[5] Bruwer, I.J. (1992) The influence of various Hemipteran species on macadamia and some factors which can limit nut damage. Ph.D. Dissertation, University of Stellenbosch, Stellenbosch.

[6] Vanden Berg, M.A., Steyn, W.P. and Greenland, J. (1999) Hemiptera occurring on macadamia in the Mpumalanga Lowveld of South Africa. African Plant Protection, 5, 89-92.

[7] Van den Berg, M.A., Steyn, W.P. and Greenland, J. (2000) Hemiptera occurring on avocado trees in the Mpumalanga Lowveld of South Africa. African Plant Protection, 6, 29-33.

[8] Saulich, A.Kh. and Musolin, D.L. (2012) Diapause in the seasonal cycle of stink bugs (Heteroptera. Pentatomidae) from the temperate zone. Entomological Review, 92, 1-26. doi:10.1134/S0013873812010010

[9] Musolin, D.L. and Saulich, A.H. (1999) Diversity of seasonal adaptations in terrestrial true bugs (Heteroptera) from the temperate zone. Entomological Science, 2, 623639. 